\title{
SINGGAH KULINER RAWA BUAYA
}

\author{
Julio Aristo Johan ${ }^{1)}$,Tony Winata ${ }^{2)}$
}

\author{
1)Program Studi S1 Arsitektur, Fakultas Teknik, Universitas Tarumanagara, juliojohan22@gmail.com \\ 2) Program Studi S1 Arsitektur, Fakultas Teknik, Universitas Tarumanagara, tonywinata@ft.untar.ac.id
}

\begin{abstract}
Abstrak
Kota Jakarta kian berkembang, terutama dalam bidang infrastruktur. Mrt pertama di Jakarta dengan rute Lebak Bulus - Bundaran Hotel Indonesia diresmikan oleh Presiden Jokowi Dodo pada tahun 2019. Dengan berkembangnya moda transportasi publik ini, maka moda transportasi publik pun menjadi sebuah unsur yang vital dalam keberlangsungan kota Jakarta. Oleh karena itu kebutuhan akan keterintegrasian moda transportasi publik dan bangunan sekitarnya pun menjadi hal yang perlu diperhatikan. Tren seperti ini sebenarnya sudah muncul pada negara-negara yang sudah lebih mutakhir moda transportasi publiknya. Singgah Kuliner Rawa Buaya hadir untuk menjadi bangunan publik yang terintegrasi dengan salah satu moda transportasi yang ada, yaitu Stasiun Rawa Buaya. Perancangan Singgah Kuliner Rawa Buaya berbatasan langsung dengan Stasiun KRL Rawa Buaya. Tema kuliner diambil karena orang yang hendak naik atau turun dari kereta yang berhenti di Stasiun KRL Rawa Buaya memilki kebiasaan untuk jajan. Namun, tempat berjualan di sekitar daerah stasiun terpencar karena mereka tidak memilki tempat yang khusus untuk berjualan. Hal ini juga didukung oleh keinginan warga setempat untuk merelokasi pedagang yang berjualan pada area sempadan sungai ke suatu tempat yang baru agar lebih tertib dan terzonasi dengan baik. Kuliner disini hadir menjadi sebuah magnet untuk orang-orang agar datang untuk singgah ke proyek. Proyek juga berinteraksi dengan sekitarnya dengan adanya program green belt serta ruang-ruang komunal yang bisa didatangi oleh siapapun. Proyek Singgah Kuliner Rawa Buaya diharapkan dapat menjadi sebuah third place bagi kawasan sekitarnya serta menjadi bangunan yang netral bagi siapapun.
\end{abstract}

Kata kunci: Jakarta; Kuliner; Singgah; Third place; Transportasi

\begin{abstract}
Jakarta is growing rapidly especially in infrastructure. In 2019 the MRT is inaugurated by President Jokowi Dodo on 24 March 2019. The MRT officially operates for the Lebak Bulus - Hotel Indonesia route. With the development of this public transport, it becomes a vital element of Jakarta. Therefore, the need for integration of public transport and public buildings has become a matter of concern. Trends like this have actually emerged in more developed countries. Rawa Buaya Culinary Stop By comes as a public building that is integrated with one of the available public transport, which is Rawa Buaya Station. Rawa Buaya Culinary Stop by is directly adjacent to the Rawa Buaya station. The culinary theme os taken the people who is going to the station or from the station of Rawa Buaya have a habit of buying some food nor snacks before and after taking the train. However, the available merchants around the station are scattered because they don't have a dedicated place to vend. This is also supported by the desire of the local people to relocate people who vends along of Kali Semanan to a new and dedicated place that is well zoned. In this project, culinary becomes a magnet for people to come and stop by the project. So the people could interact with the building and be visited by everybody.
\end{abstract}

Keywords: Culinary; Jakarta; Stop by; Transportation; Third place 


\section{PENDAHULUAN}

Kota Jakarta merupakan ibukota Indonesia dan menjadi salah satu kota metropolitan di dunia dengan jumlah penduduk hampir menyentuh angka 11 juta (Jayani, 2019). Oleh karena itu, kota Jakarta menjadi tujuan masyarakat di Indonesia untuk bermigrasi, mengadu nasib, mencari pekerjaan di ibukota, karena ibukota memiliki peluang kerja yang lebih besar. Di sisi lain, kebutuhan akan tempat tinggal dan tempat kerja semakin besar di Jakarta ini. Pembangunan pun semakin gencar dilakukan untuk mengimbangi perkembangan fisik kota. Namun, bagaimana dengan psikologi manusianya?

Konsep third place pun mulai diangkat kembali. Konsep ini diperkenalkan oleh Ray Oldenburg dalam bukunya "The Great Good Place" tahun 1997. Selain kebutuhan tempat tinggal (first place) dan tempat kerja (second place), terdapat sebuah ruang ketiga (third place) (Oldenburg, 1997). Tempat dimana individu atau kelompok dapat sekedar singgah, beristirahat melepas penat, keluar dari rutinitas mereka. Gubernur DKI Jakarta, Anies Rasyid Baswedan, juga ingin memunculkan third place di kota Jakarta. (Simanjuntak, 2019)

Melihat perkembangan kota Jakarta yang pesat, tidak hanya ketergantungan akan tempat tinggal dan tempat kerja saja yang meningkat, ketergantungan masyarakat akan transportasi publik pun meningkat. Dengan berkembangnya transportasi publik di Jakarta, masyarkat pun akan semakin bergantung pada transportasi publik kota. Konsep Transit Oriented Development (TOD) juga berkembang di Jakarta. Contohnya seperti pembangunan LRT City dan MRT Blok M yang sudah terintegrasi langsung dengan Blok M Plaza. Keberadaan third place akan menjadi terkait dengan transportasi publik karena third place erat kaitannya dengan perpindahan manusia.

Bangunan penunjang di sekitar Stasiun Rawa Buaya belum dikembangkan dengan baik juga stasiun belum terintegrasi dengan bangunan sekitarnya. Masyarakat sekitar Stasiun Rawa Buaya tentu memiliki keunikannya sendiri. Mereka cenderung untuk jajan setelah turun dari kereta maupun sebelum naik kereta. Namun, pedagang jajanan sekitar terpencar, karena mereka tidak memilki tempat yang khusus untuk berjualan. Bangunan penunjang juga merupakan salah satu unsur penilaian tingkat efisiensi dari fasilitas bagi masyarakat. Karena sebagus apapun fasilitasnya, namun penunjangnya serta area sekitarnya tidak dikembangkan dengan baik, maka masyarakat pun enggan menggunakan fasilitas tersebut. Ini masalah yang dihadapi oleh moda transportasi umum di Jakarta.

Maka dari itu, perlu ada perubahan dalam pola pikir masyarakat agar mau menggunakan moda transportasi umum. Tidak hanya dengan himbauan, namun dengan adanya perkembangan akan daerah sekitar moda transportasi umum tersebut agar lebih nyaman. Dengan berkembangnya daerah sekitar moda transportasi umum, pasti pandangan masyarakat akan berubah terhadap stigma yang ada. Stigma negatif tertanam dalam transportasi umum di Jakarta, karena dahulu terkenal rawan, sehingga masyarakat pun tidak merasakan rasa aman dan nyaman saat menggunakan transportasi umum.

Proyek yang diusulkan berupa salah satu bangunan penunjang bagi stasiun yaitu Stasiun Rawa Buaya. Bangunan ini bersifat sebagai bangunan transit bagi orang yang hendak naik atau turun dari Stasiun Rawa Buaya. Dengan beradaptasi dengan kebiasaan serta pola masyarkatnya, serta memberikan solusi terhadap masalah yang ada pada lingkungan, maka proyek menjadi bangunan yang tepat dan otentik terhadap lingkungannya. Dengan mengangkat tema kuliner, proyek ini ditujuan untuk menjadi sebuah bangunan yang khusus untuk berjualan dan menjadi area singgah bagi para pengguna kerta di Stasiun Rawa Buaya. 


\section{KAJIAN LITERATUR}

\section{The Great Good Place}

Konsep third place menurut Ray Oldenburg dalam bukunya "The Great Good Place" mendefinisikan bahwa sebuah third place adalah sebuah tempat diantara first place dan second place. First place diartikan sebagai home, sedangkan second place diartikan sebagai workplace (Oldenburg, 1997). Kehadiran third place menjadi sebuah tempat singgah dari kedua place tersebut. Adapula third place memiliki karakteristik sebagai berikut :

a. On Neutral Ground

Menciptakan zona netral, dimana semua orang bebas untuk datang kapanpun dan siapapun.

b. The Third Place as Leveler

Strata sosial dan ekonomi manusianya tidak terciri dengan jelas, orang-orang berkumpul untuk melepas penat.

c. Conversation is The Main Activity

Third Place mendorong orang untuk saling berinteraksi.

d. Accessibilty and Accomodation

Sebuah Third Place mudah diakses baik transportasi public, transportasi pribadi, dan pedestrian.

e. The Regulers

Memiliki orang yang datang rutin ke third place ini, namun bisa juga ada pendatang baru. Rasa penerimaan yang diberikan para regulers inilah yang menjadi titik keberlangsungan sebuah third place.

f. A Low Profile

Dari segi fisiknya, third place merupakan tempat yang sederhana. Seperti dalam buku "Architecture of the Everyday", sebuah bangunan menjadi bermakna karena kesederhanaanya.

g. The Mood is Playful

Kelegaan dan kebahagiaan yang di dapat dari third place.

h. A Home Away From Home

Third Place merupakan sebuah home bagi penggunanya, lebih ke arah psikologis, dimana pada sebuah third place manusia bebas untuk berekspresi. Tidak seperti di rumah yang terstruktur dan memiliki hieraki yang jelas.

Third Place ini sendiri berskala urban. Selain mampu menyelesaikan unsur urban, third place juga harus mampu menyelesaikan permasalahan pada skala neighborhood, sehingga third place tersebut menjadi sesuatu yang otentik.

\section{Open Architecture}

Open Architecure sangat terkait dengan kata openess. Menurut riset dari Ir. Agustinus Sutanto, M.Sc., M.Arch., Ph.D., ada beberapa poin penting yang terkait dengan openess : (Ir. Agustinus Sutanto, 2019)

a. Promoting Inclusiveness

b. Equal

c. A World of Strangers

d. Permeable Spaces

e. Place of Informations Exchange

Kata inclusive sendiri berarti terbuka untuk semua orang. Jadi disimpulkan bahwa arsitektur ini bisa dipakai semua orang dan semua orang boleh menggunakannya. Hal ini tentunya sangat baik karena dapat menjadi arsitektur yang bisa mendukung daerah sekitarnya. Namun, hal ini juga bisa menimbulkan permasalahan seperti keamanan. Karena semua orang dapat masuk dan menggunakannya, maka tidak menutup kemungkinan adanya orang atau kelompok yang 
negatif. Equal berarti kesetaraan, yang berarti pada arsitektur ini penggunanya harus terdapat kesetaraan. Seperti permandian pada zaman Romawi dulu. Di sana semua orang terlihat sama rata karena mereka memiliki kebutuhan yang sama. Saat manusia memilki kebutuhan yang sama, maka manusia akan menjadi lebih terbuka dengan sesamanya. Terdapat permeable spaces, di mana arsitektur tersebut memilki ruang yang bisa ditembus dalam artian arsitektur ini menghubungkan dua atau tiga komponen. Misalnya memberi akses dari halte bus ke stasiun MRT, menghubungkan daerah yang tadinya tidak ada akses, dsb.

Pada era modern ini, tempat terbuka, baik taman, bangunan publik, fasilitas umum, dsb secara tidak langsung menjadi tempat pertukaran informasi terjadi, karena terdapat komunikasi antara individu maupun kelompok. Namun, tidak semua informasi yang disebarkan adalah benar. Pada era millenials ini masyarakat sudah sangat akrab dengan teknologi, social media, serta social platform lainnya. Pertukaran informasi menjadi semakin bebas. Hal ini menimbulkan dampak positif dan juga dampak negatif. Positifnya adalah pertukaran informasi dapat berlangsung lebih cepat, negatifnya banyak juga informasi yang tidak benar ikut tersebar (hoax). Oleh karena itu, pada era millenials ini, masyarakat membutuhkan sumber informasi yang jelas. Sebuah arsitektur yang terbuka juga akan memilki beragam individu atau kelompok yang menggunakannya. Sehingga tempat ini harus menjadi tempat yang demokratis, demokratis secara perspektif yang berbeda-beda.

Open Architecture juga harus fleksibel. Karena pengguna yang beragam, maka arsitektur harus bisa memenuhi kebutuhan penggunanya juga. Manusia abad 21 memiliki sifat yang cenderung individual dan lebih sensitif akan personal space-nya, jadi sewaktu-waktu mereka juga membutuhkan waktu untuk sendiri dan tidak berinteraksi dengan orang lain. Konflik inilah yang menjadi menarik dan harus dipecahkan dengan asrsitekur. Karena kasus ini maka hybrid programming, trans programing dan multifunction space akan menjadi salah satu jalan keluar untuk memenuhi kebutuhan berbagai macam individu maupun kelompok. Sebuah Open Architecture juga tidak lepas dari kontekstualitas. Open Architecture harus bisa menjawab kebuthuh masyarakat dan daerah sekitarnya agar bisa menjadi daerah dan komunitas yang lebih baik. Kontekstualitas berbicara tentang kehidupan sehari-hari, budaya, dan sejarah daerahnya. Sehingga aspek-aspek tersebut bisa di-enhance sedemikian rupa supaya tetap lestari. (Ir. Agustinus Sutanto, 2019)

\section{Architecture of the Everyday}

Architecture of the Everyday merupakan sebuah ketertarikan yang mulai tumbuh dikalangan para arsitek dunia. Mereka membuat arsitektur untuk keluar dari seharian masyarakat yang punya rutinitas. Dibuatlah sebuah arsitektur yang tidak monumental, anti heroik, dan tidak penuh extravaganza. Architecture of the Everyday merupakan sebuah konsep arsitektur yang berbasis akan kesederhanaan, penggunaan material lokal, dan otentik serta bersahabat dengan lingkungan sekitarnya. (Steven Harris, 1998).

\section{The Rise of the Creative Class}

Richard Florida dalam bukunya The Rise of the Creative Class mengemukakan tentang creative class untuk mendeskripsikan kalangan orang yang kreatif, yang menurut teorinya menjadi salah satu kunci pertumbuhan peradaban mutakhir. (Florida, 2002) Kalangan ini mengacu kepada generasi milenial yang dikenal kreatif dan memiliki kebiasaan yang berbeda. Pola kebiasaan generasi milenial ini harus diperhatikan karena mereka merupakan generasi penerus yang akan menggunakan bangunan proyek. Analisis dari Florida juga menjadi pembahasan dalam topic memperkuat quality of place. Florida juga mngemukakan istilah street level culture, dimana musisi jalanan menjadi contohnya. Pada street level culture ini terasa sulit untuk menentukan partisipan dan pengamat, kreatifitas dan pembuatnya. Terjadi pembauran yang unik pada street level culture ini. (Florida, 2002) 


\section{Form, Space and Order}

Francis D.K. Ching mendeskripsikan ruang tidak hanya degan dibatasi tembok, namun dengan bermacam-macam elemen ruang lainnya, seperti perbedaan material, perbedaan ketinggian, suara, aroma, dan lain-lain. (Ching, 2007) Dengan memainkan elemen-elemen ruang seperti ini perbedaan ruang privat dan non privat akan semakin blur, karena konsepi orang awam perbedaan ruang adalah dengan dinding pembatas. Dengan memanfaatkan teori elemen ruang ini, akan membantu menciptakan sebuah third place dimana ruang-ruang yang ada bisa membaur dan tidak menimbulkan kesan eksklusif pada bangunan.

\section{Site Analysis}

Metode contextual analysis dari Edward T. White merupakan tahap pre-desain berupa riset, dimana pengamatan yang dilakukan fokus kepada kondisi eksisting dan potensi yang ada pada tapak. Sehingga kita tahu betul bagaimana kondisi tapak dan dapat memproyeksikan bagaimana interaksi keadaan yang ada dengan bangunan yang akan dirancang. (White, 1983) Dengan metode ini, respon bangunan terhadap lingkungannya menjadi sesuatu yang otentik dan tepat dalam menghadapi apa yang sudah ada.

\section{METODE}

Metode contextual analysis pertama dilakukan untuk mengkaji data yang ada pada lokasi existing yaitu di stasiun kereta Rawa Buaya. Kondisi lingkungan dan pergerakan manusia menjadi fokus utama dalam mendesain karena bangunan yang akan dirancang merupaka salah satu bangunan penunjang dari fasilitas transportasi tersebut. Survey juga dilkakukan untuk mengetahui kebiasaan manusianya lebih dalam. Pengumpulan data dari peraturan tata kota juga dilakukan agar bangunan yang dirancang sesuai dengan peraturna dan peruntukan yang berlaku. Serta dilakukan studi literatur dengan proyek serupa agar dalam mendesain memiliki sebuah acuan yang tepat. Dengan metode ini, perancangan proyek tidak lari dari semestinya.

Melihat generasi yang sekarang dan yang akan datang merupakan generasi milenial, maka kebutuhan ruang untuk mayoritas penggunakan bangunan akan berbeda karena generasi milenial merupakan generasi yang unik dan memilki kebiasaan yang berbeda karena perkembangan teknologi yang terjadi seiring berjalannya waktu.

Metode komparasi juga dilakukan untuk membandingkan ide-ide dan kesimpulan yang ada dari data yang dimiliki dengan bangunan dan teori yang bersangkutan. Sehingga dalam proses mendesain terdapat acuan desain agar desain yang dikeluarkan tidak lari dari tatanan yang sudah ada. Dengan metode-metode ini, desain yang dihasilkan menjadi otentik terhadap lingkungan dan permasalahan yang ada.

\section{DISKUSI DAN HASIL}

Lokasi tapak terpilih berada di Jalan Stasiun Rawa Buaya, RT.1/RW.7, Duri Kosambi, Cengkareng, Jakarta Barat, DKI Jakarta, 11750 dengan luas $4.320 \mathrm{~m}^{2}$. Dengan peraturan tapak sebagai berikut: 


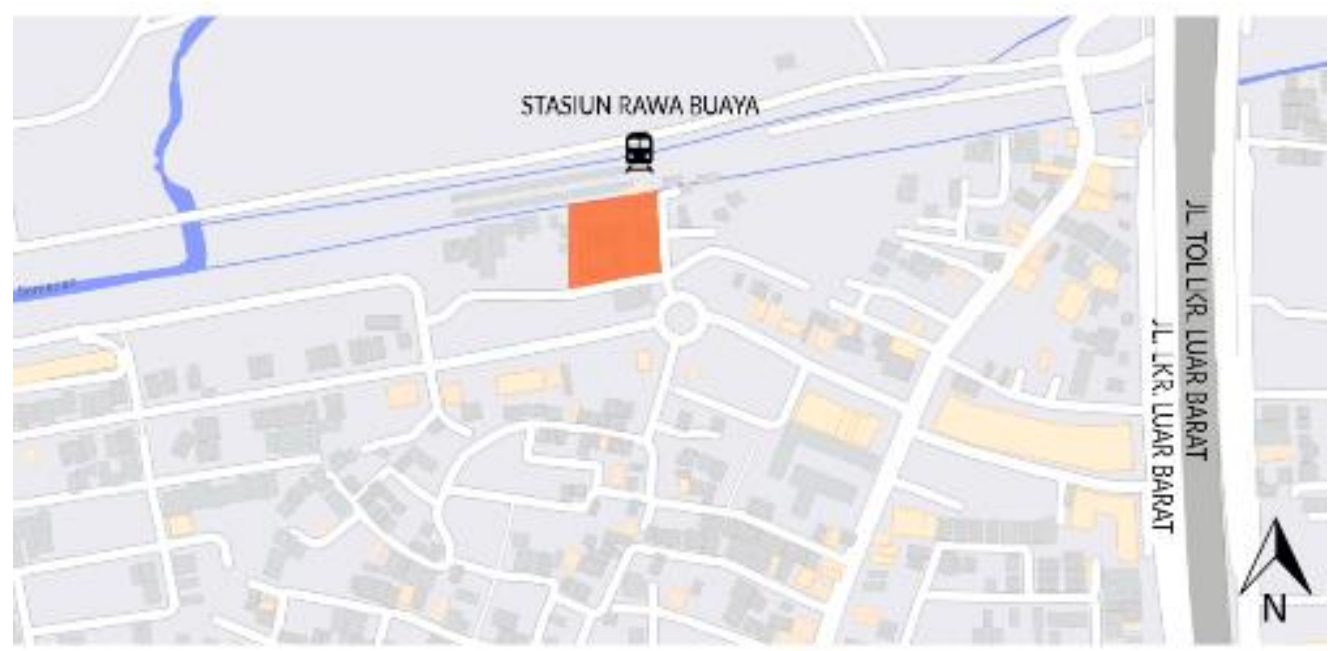

Gambar 1. Lokasi Proyek

Sumber : Data Pribadi 2020

$\begin{array}{lll}\text { KDB } & : 60 \% & : 2.592 \mathrm{~m}^{2} \\ \text { KDH } & : 20 \% & : 864 \mathrm{~m}^{2} \\ \text { KLB } & : 1.2 & : 5.184 \mathrm{~m}^{2} \\ \text { KB } & : 2 & \end{array}$

Tipe bangunan deret (DKI, Jakarta Satu). Proyek berbatasan secara langsung dengan:

a. Batas Utara : Kali Semanan dan Stasiun Rawa Buaya

b. Batas Selatan : Jalan Dharma Kencana dan Ruko Taman Semanan Indah

c. Batas Timur : Jalan Stasiun Rawa Buaya dan Area Parkir Stasiun Rawa Buaya

d. Batas Barat : Tanah Kosong

Karena berbatasan langsung dengan sungai, maka berlaku peraturan garis sempadan sungai dari Peraturan Menteri Pekerjaan Umum dan Perumahan Rakyat Republik Indonesia nomor 28/PRT/M/2015, yaitu paling sedikit berjarak 10 (sepuluh) meter dari tepi kiri dan kanan palung sungai sepanjang alur sungai, dalam hal kedalaman sungai kurang dari atau sama dengan 3 (tiga) meter. (Indonesia, 2015). Sedangkan untuk batas Barat akan nersinggungan langsung dengan bangunan sebelahnya karena tipe bangunan deret. Pada bangunan ini terdapat program utama berupa kuliner serta program penunjang lainnya yaitu rekreasi. Bangunan ini juga memperhatikan sirkulasi manusia yang sudah ada sehingga sirkulasi manusia menjadi potensi bagi bangunan. Dengan menarik pedestrian yang ada masuk ke dalam bangunan, bagunan pun akan menjadi lebih hidup dan pedestrian pun mau singgah pada bangunan proyek.

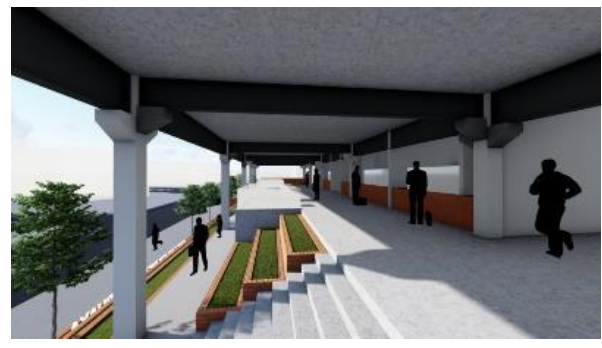

Gambar 2. Perspektif Tangga

Sumber: Data Pribadi 2020

Dengan memberikan akses tangga pada bagian luar bangunan dan tidak ada pembatas, pedestrian bebas untuk keluar masuk area tapak. Pembauran antara ruang dalam dan ruang luar juga dibuat sesamar mungkin agar tidak ada kesan eksklus pada bangunan. Pada lantai 
dasar terdapat lot untuk berjualan serta program penunjang lainnya seperti wastafel, toilet, dsb. Hal ini diciptakan untuk menjadi magnet bagi pedestrian yang lewat, sehingga mereka tertarik untuk masuk ke area tapak lebih dalam. Yang menjadi fokus pada lantai dasar adalah penciptaan innercourt pada bagian belakang bangunan yang bersinggungan langsung dengan green belt. Ada pula sirkulasi vertikal sebagai berikut:
a. 2 buah lift pengunjung
b. 2 buah tangga pengunjung
c. 1 buah lift barang
d. 1 buah tangga servis

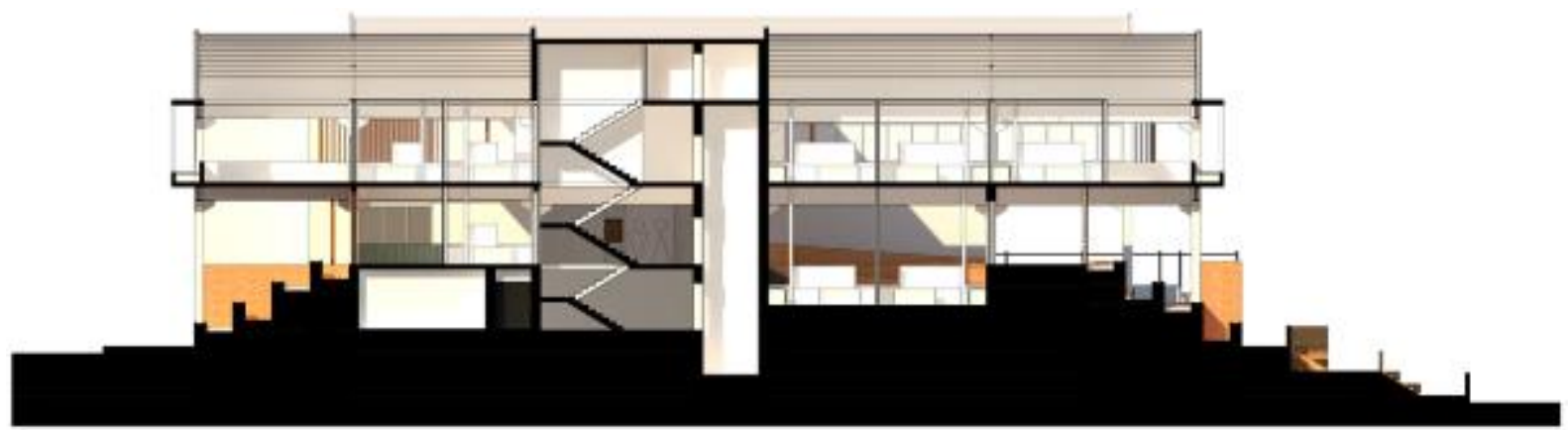

Gambar 3. Potongan Sirkulasi Vertikal Sumber : Data Pribadi 2020

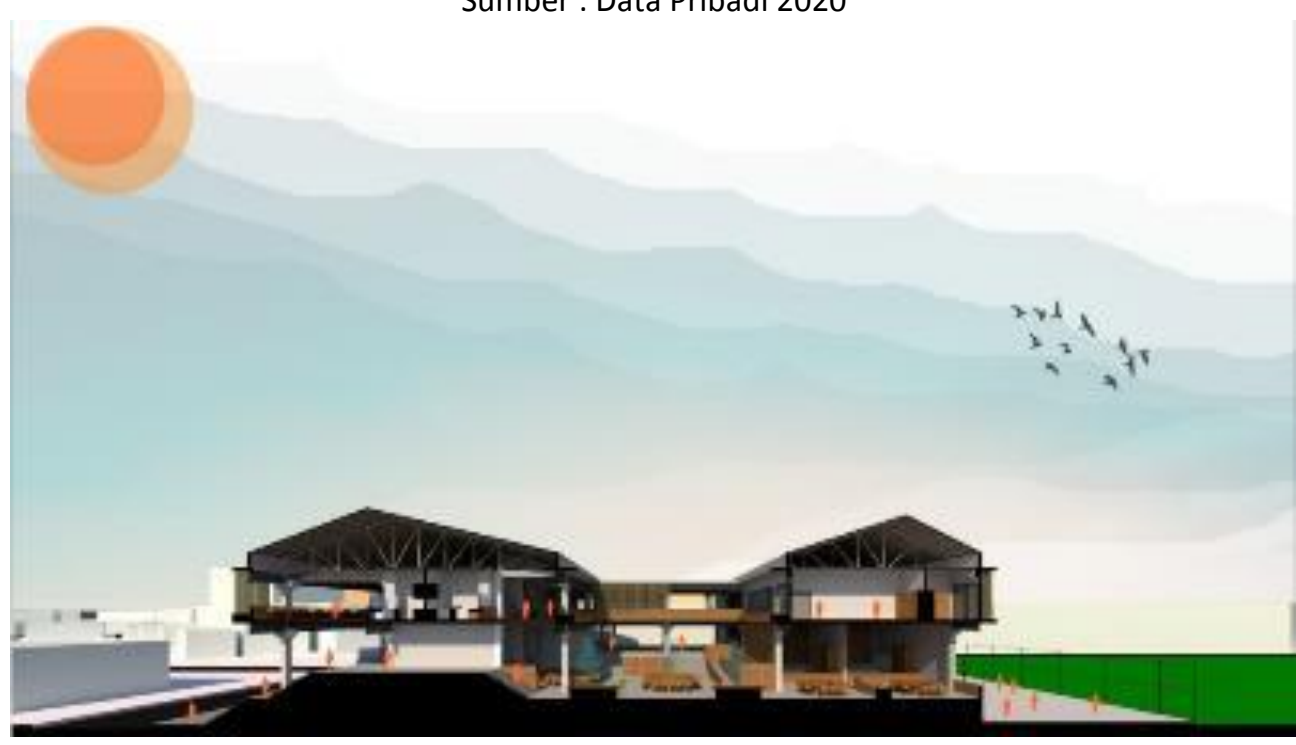

Gambar 4. Potongan Perspektif Memotong Innercourt

Sumber : Data Pribadi 2020 

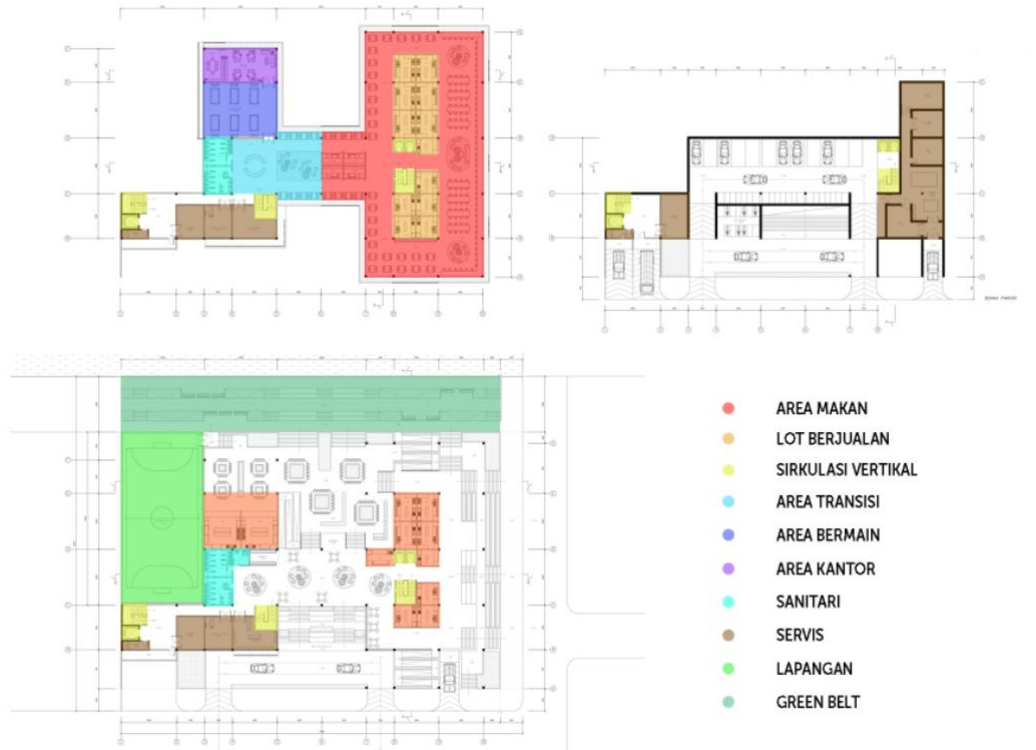

Gambar 5. Pembagian Program Bangunan Sumber : Data Pribadi 2020

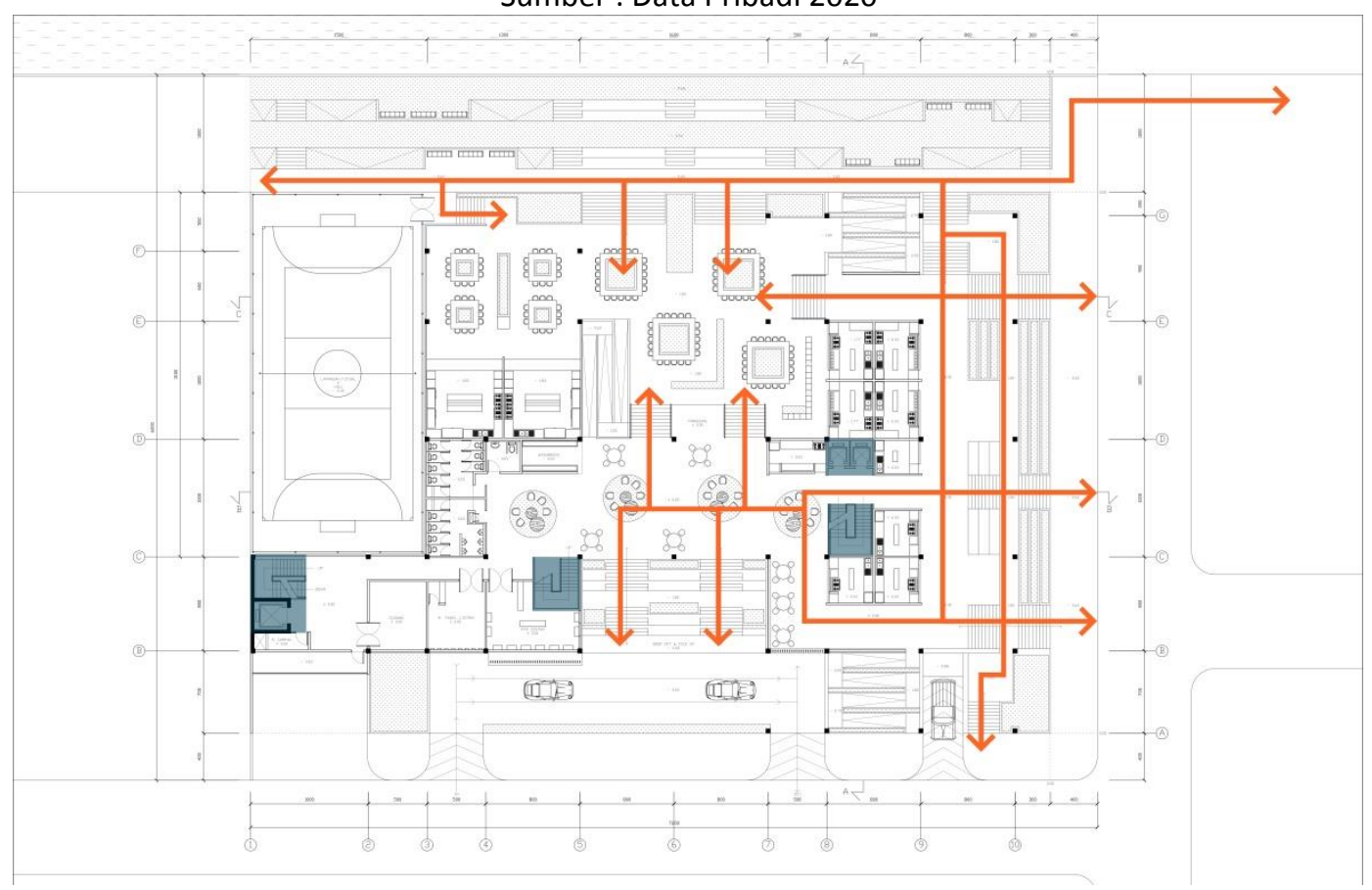

Gambar 6. Denah Lantai 1 dan Alur Sirkulasi Sumber : Data Pribadi 2020

Sirkulasi manusia di lantai dasar diciptakan begitu bebas sehingga terjadi interaksi antara ruang luar dan dalam. Serta bulrring yang terjadi antara zona privat dan non privat juga tercipta. Pengguna bangunan bebas darimana pun, termasuk dari green belt pada bagian belakang bangunan. Klimaks terdapat di innercourt. 


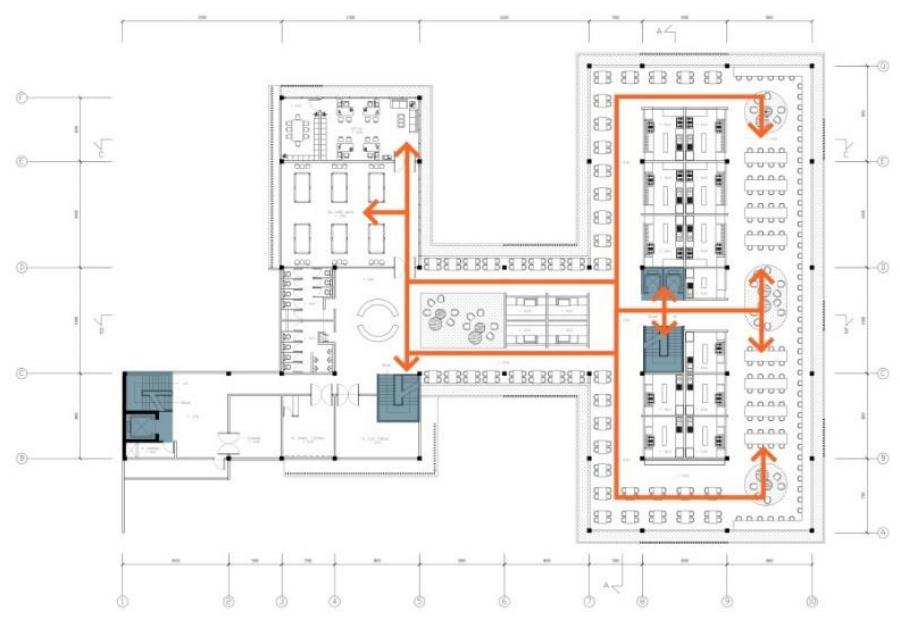

Gambar 7. Denah Lantai 2 dan Alur Sirkulasi Sumber : Data Pribadi 2020

Sirkulasi manusia di lantai dua juga diciptakan bebas, namun ada perbedaan dua zona yaitu zona kuliner dan zona bermain. Konektor pada bagian tengah bangunan merupakan konektor yang berfungsi sebagai komunitas massa dan blurring. Massa kanan merupakan zona kuliner, sedangkan massa kiri merupakan zona bermain.

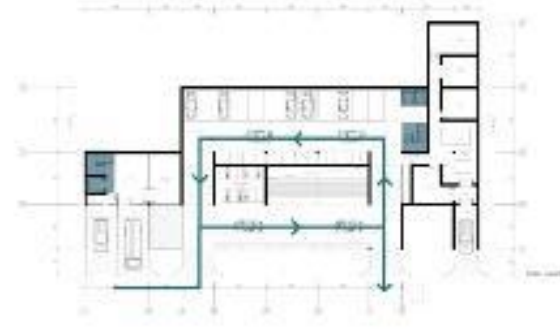

Gambar 8. Denah Parkir dan Alur Sirkulasi Sumber : Data Pribadi 2020

Sirkulasi parkir dibuat memilki loop dengan drop off sebelah kiri, sesuai dengan karakteristik kendaraan di Indonesia. Area parkiran ini bukan di basement melainkan ada di bagian kolong bangunan.

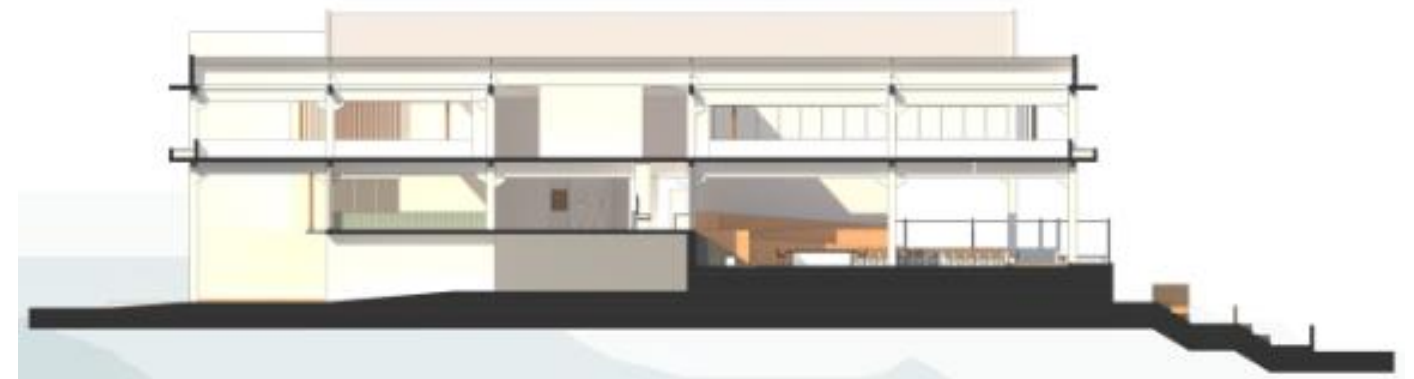

Gambar 9. Potongan Bangunan Memotong Area Parkir

Sumber : Data Pribadi 2020 


\section{KESIMPULAN DAN SARAN}

Seiring berkembangnya zaman serta infrastruktur negara, terutama dalam bidang transportasi, tentu perlu diimbangi dengan fasilitasnya, salah satunya adalah bangunan penunjang. Fasilitas penunjang merupakan salah satu aspek penting dalam penilaian efisiensi infrastruktur dari para penggunanya. Pola pergerakan dan kebiasaan para pengguna inilah yang harus dianalisis, agar kita tahu apa yang sebenarnya dibutuhkan oleh para pengguna infrastuktur tersebut. Proyek ini diharapkan mampu menjadi contoh perkembangan bangunan penunjang di sekitar stasiun kereta api, yang merupakan salah satu infrastruktur negara dalam lingkup moda transportasi. Dengan memperhatikan pola dan kebiasaan penggunanya, bisa ditarik kesimpulan program apa yang tepat guna. Sehingga tidak menjadi sebuah proyek musiman, namun menjadi bagian dari keseharian mereka.

Pengembangan infrastruktur seharusnya diimbangi dengan pengembangan fasilitas penunjangnya, seperti bangunan penunjang, maupun infrastruktur lain yang sederhana seperti jalur pedestrian, trotoar, berserta kelengkapan lainnya. Karena dengan berkembangnya fasilitas penunjang dari sebuah infrastruktur, tentu akan meningkatkan efisiensi serta kenyamanan dari infrastruktur tersebut. Sehingga, semakin banyak orang yang memilih menggunakan transportasi umum seperti kereta api.

\section{REFERENSI}

Ching, F. D. (2007). Form, Space and Order. New Jersey: John Wiley \& Sons.

DKI, P. D. (2019). Diunduh 9 Juli 2020, Jakarta Satu, https://jakartasatu.jakarta.go.id/portal/apps/webappviewer/index.html?id=ee9940006aa e4a268716c11abf64565b

Florida, R. (2002). The Rise of the Creative Class. New York: Basic Books.

Indonesia, M.P. (2015). Peraturan Menteri Pekerjaan Umum dan Perumahan Rakyat Republik Indonesia (nomor 28). Indonesia

Jayani, D. H., (2019), Proyeksi Jumlah Penduduk DKI Jakarta, diunduh10 September 2019, databoks: https://databoks.katadata.co.id/datapublish/2019/09/10/jumlah-pendudukdki-jakarta-mencapai-105-juta-jiwa

Oldenburg, R. (1997). The Great Good Place. United States of America: Da Capo Press

Steven Harris, D. B. (1998). Architecture of the Everyday. New York: Princeton Architectural Press

Sutanto, A. (2019). Open Architecture. Materi Kuliah Tamu Stupa 8 Prodi S1 Arsitektur UNTAR.

White, E. T. (1983). Site Analysis. Tallahassee: Architectural Media Ltd. 